\title{
A preparação da Vigilância em Saúde para atuação em eventos de massa: produção normativa
}

The Health Surveillance preparedness for mass gatherings: rulemaking on health

\section{Cássia de Fátima Rangel Fernandes ${ }^{1}$}

Resumo: Sediar eventos de massa traz inúmeros desafios para um país, podendo, do ponto de vista da saúde pública, impactar negativamente a localidade que os sedia. Evidenciar se o Brasil conta com arcabouço normativo suficiente sobre essa matéria, para avaliar a preparação das vigilâncias em saúde para atuar em eventos de massa. Por meio da análise documental realizada nos sistemas de informação legislativa do Senado Federal (SICON), da Presidência da República (Portal da Legislação) e do Ministério da Saúde (Saúde Legis). Verificou-se que não existem, em nosso arcabouço jurídico, leis nem decretos que tratem da gestão dos riscos à saúde em eventos de massa. A matéria é regulada em normas infralegais, por meio de portarias ministeriais e resoluções da diretoria colegiada da Anvisa. Nos últimos anos, a produção normativa necessária à atuação dos agentes de vigilância em saúde mostrou avanços significativos quanto ao desenho das responsabilidades das esferas de gestão do SUS para o planejamento e execução de ações de vigilância em saúde em megaeventos. Há, contudo, lacunas importantes na legislação sanitária federal que precisam ser supridas de modo a prover as carências do ordenamento jurídico e dar respaldo legal para atuação das vigilâncias em situações de crise e emergências que possam vir a ocorrer em eventos de massa. Desse modo, a necessidade de atualização e edição de normas jurídicas que atendam às especificidades dadas por esses megaeventos em razão de que os agentes de vigilância em saúde são agentes públicos que têm de pautar suas ações pelo Princípio de Legalidade.

Palavras-chave: Eventos de massa; Vigilância em saúde; Direito Sanitário; Produção normativa.

\begin{abstract}
Hosting mass gathering brings many challenges for a country, and may, from the standpoint of public health, negatively impact the city that hosts them. To reveal whether Brazil has sufficient normative framework on this matter to assess the readiness of health surveillances to act in mass gatherings. Analysis of documents held in legislative information systems of the Federal Senate (SICON), the Presidency (Portal da Legislação) and the Ministry of Health (Saúde Legis). There are not, on our legal framework, laws or ordinances dealing with the management of health risks at mass gatherings. The area is regulated by ministerial decrees and resolutions of the executive board of Anvisa. In recent years, the rules production required for the performance of health surveillance agents showed significant progress on the design of responsibilities of the management spheres of the Unified National Health System (SUS) for planning and implementing health surveillance activities in mega-events. However, there are important gaps in federal health
\end{abstract}

\footnotetext{
${ }^{1}$ Biomédica, Especialista em Direito Sanitário, Mestre em Saúde Pública e Meio Ambiente. Consultora técnica da Secretaria de Vigilância em Saúde do Ministério da Saúde (SVS/MS). Brasília, Brasil. E-mail: cassia.rangel@gmail.com
} 
legislation that must be met in order to provide the necessities of law and give legal support to operations of surveillance in crisis situations and emergencies that may occur at mass gatherings. Conclusion: there is a pressing need for updating and editing legal standards that meet the specifics given by these mega-events due to the fact that health surveillance agents are government officials who have to guide their actions by the Principle of Legality.

Keywords: Mass gathering; Health surveillance; Health Law; Rulemaking on health.

Resumen: Ser sede de eventos de masa trae aparejado innumerables desafíos para un país, pudiendo, desde el punto de vista de la salud pública, impactar negativamente en él. Evidenciar que Brasil cuenta con un ordenamiento jurídico suficiente, para evaluar la preparación de las vigilancias en salud para actuar en eventos de masa. Análisis documental hecho en los sistemas de información legislativa del Senado Federal (SICON), de la Presidencia de la República (Portal de Legislación) y del Ministerio de Salud (Saúde Legis). No existe en nuestro marco jurídico, leyes ni decretos que aborden la cuestión de gestión de riesgos de salud en eventos de masa. La temática es regulada por normas infra legales, porterías ministeriales y resoluciones de la directoria colegiada de Anvisa. En los últimos años, la producción normativa necesaria para actuación de los agentes de vigilancia en salud demostró avances en cuanto al diseño de responsabilidades de gestión del SUS para planificación y ejecución de acciones de vigilancia en salud en mega eventos. Hay lagunas importantes en la legislación sanitaria federal que necesitan ser suplidas de para dar respaldo legal para la actuación de las vigilancias en situaciones de crisis y emergencias que puedan ocurrir en eventos de masa. És necesaria la actualización y edición de normas jurídicas que atiendan las especificidades de esos mega eventos, en razón de que los agentes de vigilancia son agentes públicos que tienen que actuar dentro del Principio de Legalidad.

Palabras-Ilave: eventos de masa; vigilancia en salud; Derecho Sanitario; producción normativa.

\section{Introdução}

Nos últimos anos, o Brasil sediou megaeventos, também chamados de eventos de massa - sendo os mais recentes a Conferência das Nações Unidas sobre Desenvolvimento Sustentável (Rio + 20), realizada em 2012, a Copa das Confederações Brasil e a Jornada Mundial da Juventude, realizados em 2013 - e entrou, definitivamente, na agenda dos megaeventos mundiais com a realização da Copa do Mundo FIFA 2014 e dos Jogos Olímpicos e Paraolímpicos Rio 2016.

Sediar eventos de massa traz inúmeros desafios para um país, mas pode ser uma boa ocasião para a indução do desenvolvimento econômico e social e uma oportunidade para se revitalizar e modernizar áreas da gestão pública, infraestrutura e urbanismo (MASSUDA, 2012). A realização de eventos desse porte traz à tona o debate sobre 
questões que incluem o mérito das decisões político-administrativas que determinam gastos públicos; a capacidade do Estado em garantir adequada e suficiente infraestrutura de serviços públicos à população e aos turistas (NASCIMENTO, 2013); e questões relacionadas à segurança pública e sanitária de milhões de nacionais e estrangeiros que transitam pelo país durante o período de realização desses eventos.

A realização de eventos de massa tem aspectos positivos, como os já citados. Do ponto de vista da saúde pública, no entanto, podem impactar negativamente a localidade que os sedia, pela possibilidade de sobrecarga dos serviços de saúde, do aumento do risco de transmissão de doenças infecciosas e pelo potencial para a ocorrência de emergências em saúde pública, dentre outros.

Dos eventos de massa realizados no Brasil nos últimos anos, merece destaque a Copa do Mundo da FIFA 2014 (FIFA, 2014) por ter sido um megaevento esportivo de gigantescas dimensões, abrangendo 12 cidades dos 27 estados brasileiros. Os números disponibilizados pela FIFA após sua realização refletem a complexidade da preparação para a realização de um evento desta magnitude, principalmente do ponto de vista da saúde. Destacam-se a dimensão dos números que refletem a movimentação de pessoas no país em um curto período de tempo: 5.154.386 pessoas participaram das Fan Fests da FIFA; o público total das 64 partidas realizadas nos estádios brasileiros foi de 3.429.873, o maior número registrado em todos os Mundiais de Futebol desde 1994; e a média de público de 53.592 torcedores por partida também foi a maior em duas décadas. Foram distribuídas 16.746 credenciais de imprensa e realizadas 3.127 .674 operações de venda de alimentos e bebidas nos estádios ao longo da competição (FIFA, 2014).

Tendo em vista as implicações e desafios para a saúde pública que eventos de massa podem representar, buscou-se evidenciar se o Brasil conta com um arcabouço normativo suficiente sobre essa matéria, bem como identificar a natureza e o conteúdo dessas normas, sob a perspectiva de avaliação da preparação da vigilância em saúde, na esfera federal do Sistema Único de Saúde (SUS), para a atuação em eventos desta natureza. Pretendeu-se avaliar, ainda, se os eventos de massa sediados pelo Brasil tiveram caráter indutor - do ponto de vista da produção normativa - para o aprimoramento dos Sistemas Nacionais de Vigilância em Saúde e de Vigilância Sanitária para atuarem em eventos de massa, caracterizando a iniciativa e a natureza jurídica das normativas editadas. 
A partir dessa análise, procurou-se identificar os avanços do SUS, no campo da Vigilância em Saúde, para atuação em megaeventos, e as possíveis lacunas normativas ainda existentes e que precisam ser supridas, com vista aos próximos eventos de massa que serão realizados ou que possam vir a ser realizados no Brasil.

\section{Vigilância em Saúde - Competências e marco legal}

A Constituição da República Federativa do Brasil de 1988 consolidou os ideais do movimento pela Reforma Sanitária no Brasil ao trazer o reconhecimento e a proteção da saúde como direito de todos e dever do Estado. O Brasil passa a incorporar, em sua organização jurídica e social, a lógica do Estado de Direito e da democracia (AITH e DALLARI, 2009).

O reconhecimento, no texto constitucional de 1988, da saúde como um direito humano fundamental originou uma profusão de normas que objetivam garantir sua realização. O aparato normativo do Brasil, que rege os diversos aspectos relacionados ao direito à saúde - de indivíduos e da comunidade -, emana do texto Constitucional e de normas definidas em tratados internacionais, e passa por leis e normas infralegais (AITH e DALLARI, 2009). A partir da positivação do direito à saúde e do seu reconhecimento como um direito social, cabe exigir do Estado brasileiro ações concretas e efetivas que visem à redução do risco de doença e de outros agravos em busca da promoção, proteção e recuperação da saúde.

A proteção da saúde exige uma atuação permanente e vigilante dos indivíduos, das famílias, das coletividades, mas, principalmente do Estado que, por meio de um conjunto de normas jurídicas, que orientam, proíbem ou condicionam condutas, assume um papel fundamental na adoção de medidas que visem a reduzir o risco de doenças e de outros agravos à saúde da população. Quando isso não for possível, compete ao Estado adotar as medidas cabíveis para mitigar os efeitos causados. A isto chamamos princípio da segurança sanitária, que abrange a necessidade de redução de riscos existentes nas atividades humanas desenvolvidas na sociedade e que podem de alguma forma, afetar a saúde (AITH, 2007). Pode-se afirmar, portanto, que os direitos sociais, como o direito à saúde, são de realização progressiva, ou seja, dependem da ação contínua, permanente e progressiva do Estado ao longo dos anos para a proteção do direito social reconhecido (AITH, 2013). 
A Constituição de 1988, em seu art. 200, ao estabelecer as competências do SUS, lista atribuições relacionadas à segurança sanitária, isto é, atividades necessárias à redução de riscos em saúde, com um enfoque significativo para as de controle, fiscalização, vigilância e prevenção. As ações específicas de segurança sanitária são exercidas majoritariamente pela vigilância em saúde, ou seja, por meio de ações de vigilância sanitária, epidemiológica e ambiental que garantam o respeito às normas sanitárias existentes (AITH, 2007).

O princípio da segurança sanitária motivou e justificou a criação do Sistema Nacional de Vigilância Sanitária, no ano de 1999, - que compreende o conjunto de ações de vigilância sanitária executado por instituições da Administração Pública direta e indireta da União, dos estados, do Distrito Federal e dos municípios, que exerçam atividades de regulação, normatização, controle e fiscalização na área de vigilância sanitária (AITH, 2007) - e a criação da Secretaria de Vigilância em Saúde (SVS), no ano de 2003, que hoje coordena o Sistema Nacional de Vigilância em Saúde, e que foi vista como um grande avanço para o desenvolvimento das ações de controle, prevenção e proteção à saúde da população (TEIXEIRA, 2003). No âmbito da Secretaria de Vigilância em Saúde foram se desenhando e desenvolvendo os diversos campos de atuação da vigilância em saúde, além da vigilância sanitária e da vigilância epidemiológica, já tidas como as bases da vigilância em saúde.

Do ponto de vista normativo, destacam-se no campo da vigilância em saúde três leis ordinárias: Lei n 8.080, de 19 de setembro de 1990 (Lei Orgânica da Saúde), Lei no 6.259, de 30 de outubro de 1975 (dispõe sobre a organização das ações de vigilância epidemiológica, o Programa Nacional de Imunizações, à aplicação da notificação compulsória e ao atendimento de agravos coletivos à saúde, bem como os decorrentes de calamidades públicas), e Lei nº 6.437, de 20 de agosto de 1977 (define as infrações sanitárias à legislação federal e respectivas sanções).

A vigilância em saúde precisa, em consonância com o princípio da segurança sanitária e em parceria entre o Estado e a sociedade, estar organizada para atuar com foco na identificação, no controle e na eliminação de riscos à saúde, o que inclui todas as ações e serviços voltados à (AITH e DALLARI, 2009):

(i) identificação dos riscos de doenças e outros agravos à saúde; 
Cad. Ibero-Amer. Dir. Sanit., Brasília, v.4, n.1, jan/mar. 2015 ISSN 2358-1824

(ii) avaliação dos riscos identificados; adoção de medidas de prevenção e controle; combate aos riscos conhecidos;

(iii) adoção de medidas que ampliem o conhecimento sobre os eventuais riscos à saúde que possam existir nas diversas atividades humanas ou na natureza;

(iv) adoção de medidas de proteção coletiva sempre que necessário e de forma prioritária e oferecimento à sociedade de informações claras e precisas sobre os comportamentos mais adequados para a redução dos riscos à saúde.

\section{Eventos de massa e saúde}

Evento de massa é a denominação dada a atividades coletivas de natureza cultural, esportiva, comercial, religiosa, social ou política, realizadas em um período prédeterminado, com concentração ou fluxo excepcional de pessoas, de origem nacional ou internacional, e que, segundo a avaliação das ameaças, das vulnerabilidades e dos riscos à saúde pública, exijam a atuação coordenada de órgãos de saúde pública das esferas municipal, estadual e federal e requeiram o fornecimento de serviços especiais de saúde, públicos ou privados. Na literatura, eventos de massa são também chamados de grandes eventos, eventos especiais, eventos de grande porte e megaeventos (BRASIL, 2013a).

Dentre as características de eventos de massa podem-se destacar três importantes fatores do ponto de vista da saúde pública: (i) duração do evento; (ii) número de visitantes internacionais; e a (iii) extensão geográfica do evento, que pode ser realizado em vários locais em uma cidade, em várias cidades em um mesmo estado, e até mesmo em vários estados de um país (THACKWAY, 2009), como é o caso da Copa do Mundo da FIFA 2014, reconhecida como um 'megaevento esportivo'. Consideradas suas características e efeitos, os megaeventos esportivos são eventos de grande escala e curto prazo, com elevados impactos sociais, urbanísticos, econômicos e ambientais sobre as localidades que os sediam (NASCIMENTO, 2013).

Para o setor saúde, megaeventos também apresentam desafios e oportunidades. $\mathrm{O}$ aumento do fluxo e a aglomeração populacional, com concentração de pessoas de origem nacional e internacional, trazem um conjunto de riscos e ameaças para a saúde coletiva, que podem ser potencializadas em determinadas circunstâncias. A exposição de um grande número de pessoas a distintos fatores de risco leva à variação do perfil epidemiológico, resultante da importação de agentes infecciosos de outras regiões do 
mundo ou do próprio país (MASSUDA, 2012). Eventos de massa internacionais, somado a um grande número de frequentadores, com extensa aglomeração de pessoas e grande visibilidade na mídia, têm ainda como característica, o potencial elevado de risco de ocorrência de um ataque terrorista, devido ao aumento mundial da atenção em uma dada localidade por um curto período de tempo (WHO, 2008). Eventos de massa requerem, portanto, planejamento e organização de longo prazo para sua realização, o que inclui ações e serviços de saúde.

Para coordenar a preparação do SUS no recente megaevento realizado no Brasil, a Copa FIFA 2014, o Governo Federal, por meio de ação conjunta entre os Ministérios da Saúde e do Esporte, instalou, em maio de 2011, uma Câmara Temática de Saúde com o objetivo de promover a articulação das três esferas de governo, definir diretrizes organizacionais, projetos estratégicos, responsabilidades e metas, e, também, acompanhar a execução das ações preparatórias para o Mundial (MASSUDA, 2012).

Para a elaboração do Plano de Ação de Saúde para a Copa, utilizou-se como referência o Toolkit da OMS (Organização Mundial da Saúde), que traz os elementos básicos para a preparação e execução das ações de saúde para eventos de massa (MASSUDA, 2012). (Quadro 1) 
Quadro 1 - Síntese da preparação do setor saúde para eventos de massa. OMS, 2012.

\begin{tabular}{|c|c|c|}
\hline PRÉ-EVENTO & DURANTE O EVENTO & PÓS-EVENTO \\
\hline $\begin{array}{l}\text { Mapeamento e avaliação de riscos } \\
\text { relacionados ao evento } \\
\text { Preparação dos serviços para atender } \\
\text { as demandas relacionadas ao evento } \\
\text { Planejamento de respostas entre } \\
\text { áreas envolvidas para eventuais } \\
\text { emergências de saúde pública } \\
\text { Ações preventivas (informativos, } \\
\text { vacinas etc.) } \\
\text { Elaboração de plano de contenção de } \\
\text { epidemias e de prevenção de } \\
\text { endemias } \\
\text { Preparação dos profissionais de } \\
\text { saúde } \\
\text { Intensificação de controle sanitário } \\
\text { em portos, aeroportos e fronteiras }\end{array}$ & $\begin{array}{l}\text { Comunicação dos riscos de crise } \\
\text { Atendimento a aumento de } \\
\text { demanda e mudança de perfil } \\
\text { epidemiológico } \\
\text { Coordenação de respostas entre } \\
\text { áreas envolvidas para eventuais } \\
\text { emergências de saúde pública } \\
\text { Intensificação de ações de } \\
\text { comunicação em saúde } \\
\text { Contenção de epidemias e de } \\
\text { prevenção de endemias } \\
\text { Atendimento bilíngue }\end{array}$ & $\begin{array}{l}\text { Comunicação dos } \\
\text { riscos/consequências } \\
\text { Aplicação das lições } \\
\text { aprendidas para melhorar o } \\
\text { sistema de respostas } \\
\text { Vigilância da saúde pós- } \\
\text { evento } \\
\text { Avaliação pós-ações e } \\
\text { continuação }\end{array}$ \\
\hline
\end{tabular}

Fonte: Toolkit da OMS por Massuda, 2012.

A atuação da vigilância em saúde deve estar presente e é de extrema relevância em todas as fases de um evento de massa: preparação (ações pré-evento), desenvolvimento de ações durante o evento e na fase pós-evento. Envolve uma série de ações do poder público que exigem respaldo jurídico para a sua efetivação, uma vez que podem refletir em consequências tanto para indivíduos, quanto para a coletividade. É papel do Direito Sanitário dar à sociedade uma resposta adequada e funcional para temas fundamentais que a afligem e que podem representar grave risco social (AITH, 2009).

\section{Metodologia}

Trata-se de estudo descritivo e analítico, de caráter qualitativo, com base documental, utilizando a técnica de análise de conteúdo. A produção normativa analisada se restringiu à produzida na esfera federal, tendo sido selecionadas apenas as normas vigentes.

Para a identificação e busca dos atos normativos federais - leis, atos normativos originários das Casas do Congresso Nacional e atos da Presidência da República, tais como decretos - foram realizadas buscas nas bases de dados do sistema de informação 
legislativa mantido pelo Senado Federal (SICON - Sistema de Informação do Congresso Nacional) e pela Casa Civil da Presidência da República (Portal da Legislação da Presidência da República), utilizando como descritores as expressões 'eventos de massa', 'megaeventos', 'Copa do Mundo'. Para os dois sistemas de informação citados, foram utilizadas ferramentas simplificadas de pesquisa de legislação, que não permitem a delimitação de espaço temporal para a pesquisa de normas.

A pesquisa de produção normativa infralegal, direcionada para aquelas específicas à área de vigilância em saúde, foi realizada na base de dados do Sistema de Pesquisa de Legislação do Ministério da Saúde (Saúde Legis), que permite a recuperação dos atos normativos da esfera federal do SUS, utilizando os mesmos descritores (assunto), de forma isolada ou combinados entre si. Foram selecionadas como fonte de origem da produção normativa o Ministério da Saúde, a Secretaria de Vigilância em Saúde e a Agência Nacional de Vigilância Sanitária. Para delimitar o espaço temporal da pesquisa da produção normativa específica à saúde, utilizou-se como marco a realização da Copa FIFA 2014, por ter sido, dos recentes eventos de massa realizado no país, o de maior magnitude. Foi delimitado, portanto, o período compreendido entre a data de nomeação do Brasil como país sede da Copa, 30 de outubro de 2007, (FIFA, 2013) e a data anterior à cerimônia de abertura da Copa (11 de junho de 2014).

\section{Resultados}

$\mathrm{Na}$ base de dados do SICON procedeu-se a pesquisa por meio da ferramenta 'pesquisa básica' (http://legis.senado.leg.br/sicon/\#/basica) selecionando a opção 'legislação federal'. Para os argumentos de pesquisa selecionados foram devolvidos 24 resultados, dos quais 19 foram selecionados por fazerem referência a evento de massa, sendo todos relacionados à Copa do Mundo da FIFA 2014.

$\mathrm{Na}$ base de dados do Portal da Legislação da Presidência da República (http://www4.planalto.gov.br/legislacao) foi utilizada a ferramenta 'pesquisa simples' para busca de legislação federal utilizando os argumentos selecionados (denominados 'termos'). Obteve-se 30 documentos, dos quais 7 foram excluídos por: estarem fora do tema (3), terem sido revogados (3) e não ter mais eficácia (1). 
As normas encontradas no SICON (19) e as encontradas no Portal da Legislação (23) foram comparadas para eliminar as duplicidades. Obteve-se assim 25 resultados que foram classificados segundo a espécie de ato normativo (Tabela 1).

Tabela 1 - Legislação federal relacionada a eventos de massa, segundo a espécie de ato normativo. Brasil, 2014.

\begin{tabular}{lr}
\hline \multicolumn{1}{c}{ Espécie de Ato Normativo } & $\begin{array}{c}\text { № de } \\
\text { atos }\end{array}$ \\
\hline Lei Ordinária & 3 \\
Decreto & 15 \\
Medida Provisória & 3 \\
Resolução do Senado Federal & 2 \\
Ato do Presidente do Congresso Nacional & 2 \\
\hline Total & 25 \\
\hline \hline
\end{tabular}

Fontes: SICON e Portal da Legislação da Presidência da República.

Destaca-se, dentre as leis ordinárias identificadas, a Lei nำ12.663, de 5 de julho de 2012, apelidada de Lei Geral da Copa, que tem vigência fixada até 31/12/2014. A Lei foi promulgada para reger o planejamento, a organização e a realização de megaeventos específicos, incluindo a Copa do Mundo de 2014 e a Copa das Confederações de 2013, que foi considerado um evento teste para a realização da Copa do Mundo. No texto da Lei Geral da Copa, as palavras 'saúde' e 'vigilância' aparecem apenas no art. 55, que traz a responsabilidade da União em promover, para a realização dos eventos de massa de que trata a lei, a disponibilização, sem qualquer custo para o Comitê Organizador do evento, de serviços de sua competência incluindo: saúde e serviços médicos; vigilância sanitária; e alfândega.

Na base de dados do Sistema Saúde Legis (www.saude.gov.br/saudelegis), devido às características da interface de pesquisa do sistema, foram realizadas diferentes buscas, com base no tipo de norma (portaria, resolução da Diretoria Colegiada) e origem (Ministério da Saúde, Agência Nacional de Vigilância Sanitária, Secretaria de Vigilância em Saúde). 
Foram identificadas 40 portarias do Ministério da Saúde publicadas no período de pesquisa, das quais foram selecionadas 5 relacionadas a eventos de massa e à Copa FIFA 2014.

Ao realizar pesquisas de informações sobre a Copa FIFA 2014 em site de buscas de conteúdo na internet, foi localizada uma importante portaria relacionada a eventos de massa que não havia sido localizada nas pesquisas feitas no Sistema Saúde Legis, uma vez que não possui, em sua ementa, nenhuma palavra contida nos descritores definidos.

A Portaria $n^{0}$ 2.982, de 15 de novembro de 2011, trata da regulamentação de incentivo financeiro destinado a laboratórios de saúde pública estaduais, municipais e do Distrito Federal, das sedes da Copa FIFA 2014, "[...] considerando a necessidade de fortalecimento da capacidade analítica para as ações de vigilância sanitária dos laboratórios estaduais e municipais de saúde pública, com vistas a atender às demandas decorrentes da realização de grandes eventos de massa" (BRASIL, 2011a). Tendo em vista sua relevância para as ações de vigilância em saúde, essa portaria também foi considerada para a análise de conteúdo realizada neste estudo. (Quadro 2) 
Quadro 2 - Portarias do setor saúde relacionadas a eventos de massa. Ministério da Saúde (Brasil), 2011-2014.

\begin{tabular}{|c|c|c|}
\hline & Epígrafe & Ementa \\
\hline 1 & $\begin{array}{l}\text { Portaria } \text { n}^{\circ} 2.981 \text {, de } \\
15 \text { de novembro de } \\
2011\end{array}$ & $\begin{array}{l}\text { Institui o incentivo financeiro destinado aos Estados, Distrito Federal e } \\
\text { Municípios para fortalecimento das ações de vigilância sanitária } \\
\text { relacionadas a grandes eventos de massa, na forma do Bloco de } \\
\text { Financiamento de Vigilância em Saúde. }\end{array}$ \\
\hline 2 & $\begin{array}{l}\text { Portaria } \text { no }^{\circ} .982, \text { de } \\
15 \text { de novembro de } \\
2011\end{array}$ & $\begin{array}{l}\text { Regulamenta o incentivo financeiro destinado Laboratórios de Saúde } \\
\text { Pública Estaduais, Municipais e do Distrito Federal, para a execução das } \\
\text { ações laboratoriais de vigilância sanitária. }\end{array}$ \\
\hline 3 & $\begin{array}{l}\text { Portaria } n^{\circ} 817 \text {, de } 10 \\
\text { de maio de } 2013\end{array}$ & $\begin{array}{l}\text { Aprova as diretrizes nacionais para a elaboração e execução do projeto- } \\
\text { piloto de categorização dos serviços de alimentação para a Copa do } \\
\text { Mundo FIFA } 2014 \text {. }\end{array}$ \\
\hline 4 & $\begin{array}{l}\text { Portaria } n^{\circ} 1.139 \text {, de } \\
10 \text { de junho de } 2013\end{array}$ & $\begin{array}{l}\text { Define, no âmbito do Sistema Único de Saúde (SUS), as } \\
\text { responsabilidades das esferas de gestão e estabelece as Diretrizes } \\
\text { Nacionais para Planejamento, Execução e Avaliação das Ações de } \\
\text { Vigilância e Assistência à Saúde em Eventos de Massa. }\end{array}$ \\
\hline 5 & $\begin{array}{l}\text { Portaria } n^{\circ} 1.222, \text { de } \\
5 \text { de junho de } 2014\end{array}$ & $\begin{array}{l}\text { Dispõe sobre as regras especiais e a competência para autorizar a } \\
\text { concessão de diárias e passagens para deslocamentos aos servidores e } \\
\text { empregados públicos no âmbito do Ministério da Saúde e autarquias e } \\
\text { fundações públicas a ele vinculadas em decorrência da Copa do Mundo } \\
\text { FIFA 2014. }\end{array}$ \\
\hline 6 & $\begin{array}{l}\text { Portaria no } 464, \text { de } 9 \\
\text { de junho de } 2014\end{array}$ & $\begin{array}{l}\text { Fica subdelegada competência aos dirigentes máximos da Fundação } \\
\text { Nacional de Saúde (FUNASA), da Fundação Oswaldo Cruz (FIOCRUZ), } \\
\text { da Agência Nacional de Vigilância Sanitária (ANVISA) e da Agência } \\
\text { Nacional de Saúde Suplementar (ANS) para autorizar a concessão de } \\
\text { diárias e passagens para deslocamentos dos respectivos servidores e } \\
\text { empregados públicos em decorrência da Copa do Mundo FIFA 2014, } \\
\text { vedada nova subdelegação. }\end{array}$ \\
\hline
\end{tabular}

Fonte: Saúde Legis, 2014.

Na pesquisa por resoluções da Diretoria Colegiada da Anvisa (RDC), observou-se que o sistema não foi capaz de buscar apenas as normas que continham os descritores inseridos, não fazendo assim uma seleção criteriosa das normas. Ao revés, parece ter devolvido todas as RDC publicadas no período analisado. Essa falha do sistema tornou oneroso o processo de pesquisa, uma vez que houve a necessidade de leitura de 245 ementas. 
Nessa pesquisa por RDC, foram registradas apenas 5 que tratam, direta (4) ou indiretamente (1), de eventos de massa. No entanto, só foram consideradas as RDC vigentes, sendo, portanto excluída a RDC nำ 28, de 28 de maio de 2012, que dispõe sobre o controle sanitário de bens e produtos procedentes do exterior destinados à utilização na Rio+20, por ter sua vigência expirada 30 dias após o encerramento do evento. A RDC ํㅜ 2, de 2013, não traz em seu texto menção específica a grandes eventos, entretanto foi selecionada por se tratar da regulamentação da importação de amostras e kits de coleta de amostras para teste antidoping com finalidade esportiva. (Quadro 3)

Quadro 3 - Resoluções da Diretoria Colegiada da Anvisa (RDC) relacionadas a eventos de massa. Anvisa, 2013-2014.

\begin{tabular}{|c|l|l|}
\hline \multicolumn{1}{|c|}{ Epígrafe } & \multicolumn{1}{c|}{ Ementa } \\
\hline 1 & $\begin{array}{l}\text { RDC } \mathrm{n}^{\circ} \text { 13, de 28 de } \\
\text { março de 2014 }\end{array}$ & $\begin{array}{l}\text { Regulamenta a prestação de serviços de saúde em eventos } \\
\text { de massa de interesse nacional e dá outras providências. }\end{array}$ \\
\hline 2 & $\begin{array}{l}\text { RDC no 33, de 5 de } \\
\text { junho de 2014 }\end{array}$ & $\begin{array}{l}\text { Dispõe sobre as responsabilidades para a prestação de } \\
\text { serviços de alimentação em eventos de massa. }\end{array}$ \\
\hline 3 & $\begin{array}{l}\text { RDC no 2, de 4 de } \\
\text { janeiro de 2013 }\end{array}$ & $\begin{array}{l}\text { Estabelece normas de controle sanitário sobre a entrada de } \\
\text { bens e produtos procedentes do exterior destinados à } \\
\text { utilização em eventos de grande porte no País. }\end{array}$ \\
\hline 4 & $\begin{array}{l}\text { RDC 10, de } 6 \text { de } \\
\text { março de 2013 }\end{array}$ & $\begin{array}{l}\text { Dispõe sobre a importação de amostras e kits de coleta de } \\
\text { amostras sujeitos ao regime de vigilância sanitária destinados } \\
\text { a testes de controle de dopagem. }\end{array}$ \\
\hline \hline
\end{tabular}

Fonte: Saúde Legis, 2014.

Na Tabela 2 é apresentado o consolidado das 35 normas jurídicas sobre eventos de massa identificadas, segundo a espécie de ato normativo e a matéria. 

Cad. Ibero-Amer. Dir. Sanit., Brasília, v.4, n.1, jan/mar. 2015 ISSN 2358-1824

Tabela 2 - Normas jurídicas sobre de eventos de massa, segundo a espécie e a matéria. Brasil, 2014.

\begin{tabular}{|c|c|c|c|c|c|c|c|c|c|c|c|c|c|c|c|c|c|c|}
\hline \multirow[t]{2}{*}{ Espécie } & \multicolumn{2}{|c|}{$\begin{array}{l}\text { Matérias } \\
\text { específicas } \\
\text { à Saúde }\end{array}$} & \multicolumn{2}{|c|}{$\begin{array}{l}\text { Aspectos } \\
\text { gerais } \\
\text { sobre } \\
\text { realização } \\
\text { de eventos } \\
\text { de massa* }\end{array}$} & \multicolumn{2}{|c|}{$\begin{array}{c}\text { Financiamento } \\
\text { de } \\
\text { Infraestruturas } \\
\text { para a Copa }\end{array}$} & \multicolumn{2}{|c|}{$\begin{array}{l}\text { Organização do } \\
\text { Governo para } \\
\text { gestão das ações } \\
\text { governamentais } \\
\text { na Copa }\end{array}$} & \multicolumn{2}{|c|}{$\begin{array}{l}\text { Medidas } \\
\text { tributárias }\end{array}$} & \multicolumn{2}{|c|}{$\begin{array}{c}\text { Premiação } \\
\text { /menção } \\
\text { honrosa a } \\
\text { jogadores }\end{array}$} & \multicolumn{2}{|c|}{$\begin{array}{c}\text { Flexibilização } \\
\text { do horário de } \\
\text { transmissão } \\
\text { da "Voz do } \\
\text { Brasil" } \\
\text { durante a } \\
\text { Copa }\end{array}$} & \multicolumn{2}{|c|}{$\begin{array}{l}\text { Regras } \\
\text { especiais } \\
\text { para } \\
\text { concessão } \\
\text { de diárias e } \\
\text { passagens }\end{array}$} & \multicolumn{2}{|c|}{$\begin{array}{c}\text { Outras } \\
\text { matérias }\end{array}$} \\
\hline & № & $\%$ & № & $\%$ & № & $\%$ & № & $\%$ & № & $\%$ & № & $\%$ & № & $\%$ & № & $\%$ & № & $\%$ \\
\hline Leis & - & - & 1 & 2,9 & 1 & 2,8 & - & - & 1 & 2,9 & - & - & - & - & - & - & - & - \\
\hline $\begin{array}{l}\text { Medidas } \\
\text { Provisórias }\end{array}$ & - & - & - & - & 1 & 2,8 & - & - & 1 & 2,9 & - & - & 1 & 2,9 & - & - & - & - \\
\hline $\begin{array}{l}\text { Resoluções do } \\
\text { Senado }\end{array}$ & - & - & - & - & 2 & 5,7 & - & - & - & - & - & - & - & - & - & - & - & - \\
\hline $\begin{array}{l}\text { Atos da } \\
\text { Presidência do } \\
\text { Senado }\end{array}$ & - & - & - & - & 1 & 2,8 & - & - & - & - & - & - & 1 & 2,9 & - & - & - & - \\
\hline Decretos & - & - & 1 & 2,9 & - & - & 5 & 14,3 & 2 & 5,7 & 2 & 5,7 & - & - & 2 & 5,7 & 3 & 8,6 \\
\hline Portarias & 4 & 11,4 & - & - & - & - & - & - & - & - & - & - & - & - & 2 & 5.7 & - & - \\
\hline $\begin{array}{l}\text { Resoluções } \\
\text { Anvisa }\end{array}$ & 4 & 11,4 & - & - & - & - & - & - & - & - & - & - & - & - & - & - & - & - \\
\hline Total & 8 & 22,8 & 2 & 5,8 & 5 & 14,1 & 5 & 14,3 & 4 & 11,5 & 2 & 5,7 & 2 & 5,8 & 4 & 11,4 & 3 & 8,6 \\
\hline
\end{tabular}

${ }^{*}$ Copa das Confederações, Copa FIFA 2014 e Jornada Mundial da Juventude.

Fontes: SICON, Portal da Legislação da Presidência da República, Saúde Legis. Elaborada pela autora. 


\section{Discussão}

A análise da produção normativa pelo Poder Legislativo mostrou que essa teve como foco o planejamento e a organização de eventos de massa do ponto de vista do financiamento para a construção de estruturas físicas, definição de medidas tributárias especiais e flexibilização do horário de transmissão da Voz Brasil durante a Copa FIFA 2014, sem fazer menção à gestão dos riscos à saúde decorrentes da realização de eventos deste porte.

Nosso arcabouço legal, portanto, não oferece respaldo legal para a preparação, organização e atuação do setor saúde e, por conseguinte, das vigilâncias, para enfrentar os desafios postos diante de um cenário tão complexo.

A produção normativa do Poder Executivo, realizada por meio de decretos, foi abundante (15 decretos promulgados no período estudado), mas, da mesma forma, não fez menção aos aspectos de saúde relacionados aos eventos de massa, regulamentando apenas aqueles afetos aos aspectos gerais sobre sua realização; medidas tributárias; logística de recursos humanos; obras de infraestruturas nos estádios; divulgação de transparência de dados e informações relativos à Copa; exploração de sons e imagens na Copa 2006; premiação/menção honrosa a jogadores; declaração de ponto facultativo a fim de possibilitar a celebração do regresso da seleção brasileira de futebol; e organização do Governo para gestão das ações governamentais específicas para a realização da Copa FIFA 2014.

A produção normativa relacionada à saúde, com foco na vigilância em saúde, se restringiu às iniciativas do Poder Executivo por meio da produção de outras normas infralegais (portarias ministeriais e resoluções da Diretoria Colegiada da Anvisa).

Das seis portarias identificadas sobre a matéria, apenas duas não têm relação direta com o desenvolvimento de ações e serviços de saúde em eventos de massa (Portaria nº 1.222, de 5 de junho de 2014 e a Portaria nํ 464, de 2014 - dispõem sobre regras especiais para a concessão de diárias e passagens para deslocamentos de servidores e empregados públicos em decorrência da Copa FIFA 2014). A matéria das demais portarias traz aspectos importantes para o planejamento e preparação das vigilâncias para a atuação em eventos de massa. Observa-se que a produção normativa com foco na vigilância em saúde é matéria nova e teve estímulo com a realização da Copa FIFA 2014, tendo as primeiras normas sido produzidas no ano de 2011. 
Destaca-se a Portaria GM/MS no 1.139/2013 (BRASIL, 2013a) que define as responsabilidades específicas das três esferas de gestão do SUS e estabelece as Diretrizes Nacionais para o Planejamento, a Execução e a Avaliação das Ações de Vigilância e Assistência à Saúde em Eventos de Massa. Essa norma tem como finalidade prevenir e mitigar riscos à saúde a que está exposta a população em eventos de massa, utilizando-se, para isto, da definição de responsabilidades dos gestores do SUS e do estabelecimento de mecanismos para uma gestão integrada durante as fases do evento. Em seu art. 13, a portaria define que a atuação do SUS deve estar organizada em um 'plano operativo', específico para cada evento de massa, alinhado aos Planos de Emergência em Saúde e Planos de Contingência por tipologia de eventos de saúde pública (ex.: desastres naturais, surtos epidêmicos, e acidentes químicos, biológicos, radiológicos e nucleares). A Portaria traz ainda, em seu Anexo II, critérios para a avaliação do risco em eventos de massa de acordo com o impacto na saúde do público envolvido; define parâmetros mínimos que o planejamento do setor saúde deve contemplar, incluindo ações de prevenção e promoção da saúde; e define o monitoramento e avaliação das ações de vigilância à saúde. A Portaria reserva uma seção específica para as ações de vigilância em saúde, que devem ser executadas em observância ao Plano Operativo para o gerenciamento dos riscos ambientais, epidemiológicos e relacionados ao uso ou consumo de produtos e serviços de interesse à saúde.

Vê-se, portanto, que houve uma preocupação do governo em delinear os aspectos relevantes, do ponto de vista da saúde, para a preparação do setor saúde para a atuação em eventos de massa, e que isso foi feito predominantemente por iniciativa do Poder Executivo e por meio de normativas infralegais, do âmbito do sistema de saúde.

O conteúdo das demais portarias aponta para o aprimoramento das ações de vigilância sanitária, com repasse de incentivo financeiro aos estados e municípios sedes da Copa FIFA 2014, com o objetivo de fortalecer as ações de vigilância sanitária relacionadas a eventos de massa. $O$ incentivo financeiro é justificado pela necessidade de estruturação e qualificação das ações de gerenciamento de risco da vigilância sanitária, e pela necessidade de fortalecimento das ações de vigilância sanitária relacionadas a serviços de alimentação, e da capacidade analítica para a execução das ações de vigilância sanitária dos laboratórios de saúde pública, com vistas a atender as demandas decorrentes da realização de grandes eventos de massa (com foco na Copa FIFA 2014). 
As RDC publicadas no período pré-Copa também evidenciam a busca pelo aprimoramento da atuação da vigilância em saúde, especificamente da vigilância sanitária, para a atuação em eventos de massa.

Ao Poder Executivo, entretanto, em seu papel jurídico essencial enquanto regulamentador de normas, por meio da edição de normas infralegais, não é permitido alcançar temas que são de competência legislativa, como a determinação de restrições ao trânsito de pessoas, a instituição de quarentena e isolamento, a proibição da realização de eventos públicos (como encontros religiosos) e outras medidas sanitárias - previstas no Regulamento Sanitário Internacional (RSI) em caso de emergências em saúde pública que o agente sanitário pode ter que vir a empregar durante a realização de eventos de massa.

O princípio da segurança sanitária exige, portanto, uma atualização permanente da legislação sanitária, especialmente em decorrência da introdução na sociedade de novos riscos ou do agravamento de riscos já existentes Aith (2007). O Direito Sanitário carece de suprir expectativas decorrentes de um futuro incerto ou de uma grave crise, como a ocorrência de emergências de saúde pública que podem vir a ser declaradas durante a realização de um evento de massa. Essas emergências podem decorrer de situações epidemiológicas, de desastres, e em caso de desassistência à população (BRASIL, 2011b). Do ponto de vista das emergências em saúde pública, as situações epidemiológicas requerem especial atenção em megaeventos, particularmente aqueles com participação massiva de público internacional, devido ao intenso trânsito de pessoas que entram e saem do país, tendo como origem e destino os mais diversos locais do globo terrestre, proporcionando o que podemos chamar de 'transnacionalização dos riscos'.

A realização de megaeventos traz à tona, portanto, a necessidade das vigilâncias estarem preparadas e organizadas para a possibilidade de ocorrência de uma emergência em saúde pública. Entretanto, conforme afirma Romero (2013), é ainda precário o aparato legal com que contam as autoridades sanitárias, os agentes públicos e os gestores de saúde para o enfrentamento de emergências de saúde pública causadas, por exemplo, por epidemias de doenças infecciosas. Afirma que, apesar de se contar com suficiente regulamentação das atividades de vigilância sanitária e de saúde dos portos, não há normativas que permitam que a atuação das autoridades sanitárias, frente a emergências representadas por epidemias de doenças infecciosas, se faça sob o princípio da 
legalidade. Ficam, portanto, as autoridades sanitárias sem suficiente respaldo legal para implementar ações restritivas de direitos e liberdades individuais que eventualmente possam ser necessárias ao enfrentamento de situações decorrentes de emergências em saúde pública (ROMERO, 2013).

Cabe destaque, portanto, que, ao se tratar da preparação do setor saúde para a atuação em eventos de massa, em especial quanto às atribuições da vigilância em saúde, é preciso abordar dois importantes aspectos aqui discutidos: (i) o planejamento e a organização de ações específicas da vigilância em saúde para eventos de massa (ex.: gestão do risco, fiscalização de pontos de vendas de alimentos em locais do evento; importação ou entrada de produtos no país para uso e consumo durante os eventos); e (ii) a possibilidade de ocorrência de uma emergência de saúde pública.

O estudo evidencia que a abordagem das duas matérias é nova no ordenamento jurídico brasileiro, e que não há legislação federal que cuide dessas matérias. Relativamente à preparação e à realização dos eventos de massa recentemente realizados no Brasil, a produção normativa foi predominantemente de iniciativa do Executivo e feita por meio de normas infralegais.

A atuação do agente público, frente aos riscos à saúde que deve gerenciar, é dotada de uma margem de discricionariedade, sempre em benefício do interesse geral. Insere-se aí o poder de polícia administrativa. Essa extensão do poder de agir, no entanto, deve estar explicitada na lei que qualifica o exercício da autoridade. Logo, não é competente quem quer, mas quem pode, segunda a norma de Direito (Tácito, 2001). Uma vez que o agente público deve agir obedecendo ao princípio da legalidade (CF, art. 37), ficam a autoridade sanitária e o gestor público de saúde dependentes do respaldo legal para sua atuação, tornando-se reféns de situações incontroláveis, em especial quando sua atuação se revela urgente (ROMERO, 2013).

Teixeira et al (2009) aborda o esforço do Ministério da Saúde em criar um ambiente jurídico-institucional necessário para que o Brasil enfrente desafios sanitários futuros. Entretanto, a autora relata que a inclusão, nas propostas de anteprojetos de lei, de medidas restritivas à liberdade individual e coletiva, tendo em vista o controle de riscos à saúde, causou discussões acaloradas e certo mal estar entre associações e instituições acadêmicas do campo da Saúde Coletiva. 
A matéria é, de fato, delicada, uma vez que se configura como um conflito de interesses, ambos protegidos pela Constituição, entre a autoridade estatal no exercício de ações de saúde pública e a liberdade individual.

\section{Conclusão}

A produção normativa necessária à atuação dos agentes de vigilância em saúde, em relação à preparação e realização de eventos de massa em nosso país demonstrou avanços significativos, em especial no desenho das responsabilidades das esferas de gestão do SUS para o planejamento e a execução das ações de vigilância em saúde em eventos de massa.

A vigilância sanitária, no âmbito do Sistema Nacional de Vigilância Sanitária, pôde aprimorar sua atuação pautada em normas infralegais que regulamentaram temas específicos de competência dessa vigilância. A atuação das demais vigilâncias (epidemiológica, ambiental), no âmbito do Sistema Nacional de Vigilância em Saúde, também sofreu incremento com a publicação da Portaria GM/MS nํ 1.139, de 2013, em especial por trazer o arcabouço técnico para a organização das vigilâncias na preparação para a resposta a emergências em saúde pública. Isto inclui a previsão da elaboração de um Plano de Emergência e de Planos de Contingência, como o relacionado à ocorrência de eventos por agentes químico, biológico, radiológico e nuclear.

Existem, contudo, lacunas importantes na legislação sanitária federal que precisam ser supridas. Conforme alerta da OMS, no que diz respeito à implementação do RSI, é preciso avaliar a necessidade de revisão da legislação sanitária - no Brasil parcialmente regulada pela Lei no 6.259, de 1975 - de modo a suprir as carências do ordenamento jurídico e dar respaldo legal para atuação das vigilâncias em saúde em situações de crise e de emergência (ROMERO, 2013).

O Direito Sanitário deve, portanto, prover base legal para a atuação do setor saúde, inclusive para proibir e condicionar condutas, visando assegurar a saúde da população. A Lei no 6.259, de 1975, prevê o Poder de Polícia para as autoridades sanitárias responsáveis pela proteção da saúde, a fim de evitar que condutas que ofereçam risco à saúde sejam realizadas. É preciso, porém, a edição de critérios que expliquem quais os casos que irão admitir a adoção de uma medida excepcional de limitação de liberdade individual (AITH, 2007). Para a atuação das vigilâncias em saúde em eventos de massa, 
em especial quando da ocorrência de uma emergência em saúde pública, é essencial que estes critérios estejam bem definidos de modo que a saúde da população seja protegida e ainda para que a atuação autoritária do agente público seja impedida.

A realização de eventos de massa traz, portanto, desafios importantes do ponto de vista da atuação da autoridade sanitária e dos riscos sanitários a que a população pode vir a ser exposta, seja pelo intenso tráfico nacional e internacional de pessoas, seja pela possibilidade de ocorrência de emergências de saúde pública representadas por acidentes e desastres decorrentes do aglomerado de pessoas, atos de terrorismo ou epidemias, que podem ter sua magnitude amplificada em função das características peculiares desses eventos.

É premente a necessidade de atualização e/ou edição de normas jurídicas de Direito Sanitário que atendam às especificidades dadas por estes megaeventos, em especial quanto aos riscos sanitários que podem decorrer da sua realização, e ainda em razão de que os agentes de vigilância em saúde são agentes públicos que, necessariamente, têm de pautar suas ações pelo Princípio de Legalidade.

\section{Referências bibliográficas}

AITH, F. e DALLARI, S, G. Vigilância em Saúde no Brasil: Os Desafios dos Riscos Sanitários do Século XXI e a Necessidade de Criação de um Sistema Nacional de Vigilância em Saúde. São Paulo: v.10, p.94-125, jul./out. 2009. Disponível em: http://www.revistas.usp.br/rdisan/issue/view/1053. Acesso em: 24 set. 2014.

AITH, F. Institucionalização normativa de políticas públicas de saúde no Brasil: estudo de caso com o programa nacional de controle da dengue - PNCD. Revista Tempus - Actas de Saúde Coletiva, Brasília: v. 7,n.1, p.349-366, 2013. Disponível em:

http://www.tempusactas.unb.br/index.php/tempus/article/view/1301. Acesso em: 24 set. 2014.

AITH, F. Curso de Direito Sanitário - a proteção do direito à saúde no Brasil. São Paulo: Quartier Latin, 2007. 406 p.

BRASIL. Constituição da República Federativa do Brasil (1988). Brasília: Senado Federal. Disponível em:

$<$ http://www.planalto.gov.br/ccivil 03/constituicao/constituicaocompilado.htm>. Acesso em: 20 ago. 2014.

BRASIL. Ministério da Saúde. Portaria MS/GM nำ 1.139, de 10 de junho de 2013. Define, no âmbito do Sistema único de Saúde (SUS), as responsabilidades das esferas de gestão e estabelece as Diretrizes Nacionais para Planejamento, Execução e Avaliação das Ações de Vigilância e Assistência à Saúde em Eventos de Massa. Disponível em: 
$<$ http://bvsms.saude.gov.br/bvs/saudelegis/gm/2013/prt1139 1006 2013.html>. Acesso em: 29 set. 2014.

BRASIL. Ministério da Saúde. Portaria MS/GM no 1.378, de 9 de julho de 2013. Regulamenta as responsabilidades e define diretrizes para execução e financiamento das ações de Vigilância em Saúde pela União, Estados, Distrito Federal e Municípios, relativos ao Sistema Nacional de Vigilância em Saúde e Sistema Nacional de Vigilância Sanitária. Disponível em: http://bvsms.saude.gov.br/bvs/saudelegis/gm/2013/prt1378 0907 2013.html>. Acesso em: 25 set. 2014.

BRASIL. Ministério da Saúde. Portaria MS/GM no 2.982, de 15 de novembro de 2011. Regulamenta o incentivo financeiro destinado Laboratórios de Saúde Pública Estaduais, Municipais e do Distrito Federal, para a execução das ações laboratoriais de vigilância sanitária. Disponível

$<$ http://bvsms.saude.gov.br/bvs/saudelegis/gm/2011/prt2982 1512 2011.html>.Acesso em: 20 ago. 2014.

BRASIL. Presidência da República. Decreto no 7.616, de 17 de novembro de 2011. Dispõe sobre a declaração de Emergência em Saúde Pública de Importância Nacional - ESPIN e institui a Força Nacional do Sistema Único de Saúde - FN-SUS. Diário Oficial da União, Brasília, DF, 18 nov. 2011b. [on line] Disponível em: <http://www.planalto.gov.br/ccivil 03/ Ato2011-2014/2011/Decreto/D7616.htm>. [data de consulta: 20 ago. 2014].

BRASIL. Presidência da República. Lei o 6.259, de 30 de outubro de 1975. Dispõe sobre a organização das ações de Vigilância Epidemiológica, sobre o Programa Nacional de Imunizações, estabelece normas relativas à notificação compulsória de doenças, e dá outras providências. Disponível em: <http://www.planalto.gov.br/ccivil 03/leis//6259.htm>.Acesso em: 29 set. 2014.

BRASIL. Presidência da República. Lei no 6.437, de 20 de agosto de 1977. Configura infrações à legislação sanitária federal, estabelece as sanções respectivas, e dá outras providências. Brasília, DF. Disponível em: <http://www.planalto.gov.br/ccivil 03/leis/L6437.htm>. Acesso em: 29 set. 2014.

BRASIL. Presidência da República. Lei oㅡ 8.080, de 19 de setembro de 1990. Dispõe sobre as condições para a promoção, proteção e recuperação da saúde, a organização e o funcionamento dos serviços correspondentes e dá outras providências. Disponível em: < http://www.planalto.gov.br/ccivil_03/leis//8080.htm>. Acesso em: 20 ago. 2014.

FÉDÉRATION INTERNATIONALE DE FOOTBALL ASSOCIATION (FIFA). Regulations 2014 FIFA World Cup Brazil ${ }^{\mathrm{TM}}$, 3 Out. 2013. Disponível em:

$<$ http://resources.fifa.com/mm/document/tournament/competition/01/47/38/17/regulationsfw cbrazil2014 update e neutral.pdf>. Acesso em: 02 out. 2014.

FÉDÉRATION INTERNATIONALE DE FOOTBALL ASSOCIATION (FIFA). Todos os números da Copa do Mundo da FIFA (FIFA.com). Disponível em: $<$ http://pt.fifa.com/worldcup/news $/ \mathrm{y}=2014 / \mathrm{m}=9 /$ news=todos-os-numeros-da-copa-domundo-da-fifa-2443114.html>. Acesso em: 02 out. 2014. 
MASSUDA, A. Megaeventos no Brasil: oportunidades e desafios da Copa do Mundo FIFA 2014 para o Sistema Único de Saúde. Revista Brasileira de Cardiologia, v.25,n.5, p.358361, set./out. 2012. Disponível em: < http://www.rbconline.org.br/wpcontent/uploads/v25n05a00a.pdf>. Acesso em: 29 set. 2014.

NASCIMENTO, A. R. Megaeventos esportivos e responsabilidade civil do estado: fundamento e requisitos. Revista das Faculdades Metropolitanas Unidas de Direito. São Paulo: v.27,n.40, p.27-37, 2013. Disponível em: < http://www.revistaseletronicas.fmu.br/index.php/RMDIR/article/view/428>. Acesso em: 02 out. 2014].

ROMERO, L.C. O Congresso Nacional e as emergências sanitárias: a resposta do Poder Legislativo às necessidades da saúde. Dissertação de Mestrado em Saúde Coletiva. Faculdade de Ciências da Saúde, Universidade de Brasília, 2013.

TÁCITO, C. Princípio de legalidade e poder de polícia. Revista de Direito, Rio de Janeiro: v.5, n.10, p.15-25, jul./dez. 2001. Disponível em: $<$ http://www.camara.ri.gov.br/setores/proc/revistaproc/revproc2001/revdireito2001B/art pod erpolicia.pdf>. Acesso em: 26 out. 2014.

TEIXEIRA, M.G. et al. Vigilância em Saúde: É Necessária uma Legislação de Emergência. Revista de Direito Sanitário, São Paulo: v.10, n.2, p. 126-144, jul./out. 2009. Disponível em: http://www.revistas.usp.br/rdisan/issue/view/1053. Acesso em: 24 set. 2014.

TEIXEIRA, M.G.. Editorial especial: Secretaria de Vigilância em Saúde: novas perspectivas para o SUS. Revista Brasileira de Epidemiologia, São Paulo: v. 6, n.3, p. 197-199, 2003. Disponível em:

http://www.scielo.br/pdf/rbepid/v6n3/02.pdf. Acesso em: 25 set. 2014.

THACKWAY, S. et al. Should cities hosting mass gatherings invest in public health surveillance and planning? Reflections from a decade of mass gatherings in Sydney, Australia. BioMed Central Public Health, United Kingdom: 8 set. 2009, p. 9:324.Disponível em: <http://www.biomedcentral.com/content/pdf/1471-2458-9-324.pdf>.Acesso em: 29 set. 2014.

WORLD HEALTH ORGANIZATION (WHO): Communicable disease alert and response for mass gatherings: Key considerations. Genebra: 2008. Disponível em: <http://www.who.int/csr/Mass gatherings2.pdf>.Acesso em: 29 set. 2014]. 